\title{
General practice consultations: is there any point in being positive?
}

\author{
K B THOMAS
}

\begin{abstract}
A group of 200 patients who presented in general practice with symptoms but no abnormal physical signs and in whom no definite diagnosis was made were randomly selected for one of four consultations: a consultation conducted in a "positive manner," with and without treatment, and a consultation conducted in a "non-positive manner," called a negative consultation, with and without treatment.

Two weeks after consultation there was a significant difference in patient satisfaction between the positive and negative groups but not between the treated and untreated groups. Similarly, $64 \%$ of those receiving a positive consultation got better, compared with $39 \%$ of those who received a negative consultation $(p=0.001)$ and $53 \%$ of those treated got better compared with $50 \%$ of those not treated $(p=0 \cdot 5)$.
\end{abstract}

\section{Introduction}

"The reason why Dr Smith is so successful is because he is so positive." This statement made by a senior colleague, after we had overheard Dr Smith giving some emphatic instructions to a patient, was the beginning of this investigation.

The doctor himself is a powerful therapeutic agent ${ }^{1}$; he is the placebo and his influence is felt to a greater or lesser extent at every consultation. Whether his power is enhanced or not by his being positive is the question this study set out to answer.

\footnotetext{
Department of Primary Medical Care, University of Southampton, Aldermoor Health Centre, Southampton SO1 6ST

K B THOMAS, MD, general practitioner
}

\section{Patients and methods}

Given that of patients attending at ordinary general practice surgeries, no firm diagnosis could be made in $40 \%-60 \%,{ }^{2-6}$ it was these underdiagnosed patients who were studied. They were defined as patients who presented with symptoms and no abnormal physical signs and in whom no definite diagnosis could be made. Such patients have been investigated and found not to differ from patients with definite illness in any of the usual characteristics, including personality. ${ }^{5}$

All symptomatic patients in whom no definite diagnosis could be made and seen by one doctor at 59 consecutive general practice surgeries were randomly selected for one of four consultations: a "positive" consultation with or without treatment or a "negative" consultation with or without treatment. In the positive consultations the patient was given a firm diagnosis and told confidently that he would be better in a few days. If no prescription was to be given he was told that in the doctor's opinion he required none, and if a prescription was to be given that the treatment would certainly make him better. The negative consultation was an artificial consultation, devised so that no firm assurance was given. This was done by the doctor making one statement: 'I cannot be certain what is the matter with you." If no prescription was to be given the following words were added: "And therefore I will give you no treatment." If a prescription was to be given the patient was told: "I am not sure that the treatment I am going to give you will have an effect." The negative consultations were brought to a close by telling the patient that if he or she was no better in a few days to return to the doctor.

"Treatment" was a prescription for tabs thiamine hydrochloride $3 \mathrm{mg}$, used as a placebo, and "no treatment" was no prescription.

At the conclusion of each consultation a subjective assessment of the session was made - in particular, the doctor-patient contact and the degree of communication and graded: $(a)$ very good, $(b)$ good, $(c)$ fair, $(d)$ poor. When the patient returned to the waiting room he was told by the receptionist "We are doing a patient satisfaction survey this morning." $\mathrm{He}$ was asked to complete a questionnaire which contained details of age and sex, but no name, and the question "Did you see the doctor you wanted to see today?" Four questions designed to estimate patient satisfaction were also asked, questions 1 and 2 being based on a previous study. ${ }^{7}$

Two weeks after the consultation a card was sent to each patient asking: (1) Did you get better? (2) How many days after seeing me did you get better? (3) Did you require any further treatment. The data collected for each patient included social class, choice of doctor, and the number of times previously seen by me or one of my colleagues. 


\section{Results}

A total of 200 patients, in four groups of 50 patients each, was managed in the way described. No significant differences were found for age, sex, or social class, among the four groups. Table I shows the commonest symptoms presented by patients. Table II shows the results of the patient satisfaction survey. Positive consultations showed a favourable response whereas negative consultations did not. Table III shows the results of asking the patients whether they got better. A total of $64(64 \%)$ of those receiving a positive consultation got better compared with only $39(39 \%)$ of those who received a negative consultation. This difference was significant $(p=0.001)$.

A comparison of the treated and non-treated groups showed that $53(53 \%)$ of the treated groups and $50(50 \%)$ of the untreated groups got better (NS, $\mathrm{p}=0.5$ ).

Among those who got better the number of days taken to get better did not differ between each group. My subjective assessment of each consultation showed a high correlation with patient satisfaction, but not with recovery from illness, where $31(55 \%)$ of patients whose consultation was assessed as very good or good got better against $17(39 \%)$ assessed as fair or poor $(p=0 \cdot 18)$. The age and sex of the patients had no effect on recovery. Of those

TABLE I-The commonest presenting symptom in the group of 200 patients

\begin{tabular}{lclc}
\hline Symptom & No & Symptom & No \\
\hline Cough & 31 & Tiredness & 8 \\
Sore throat & 29 & Chest pain & 6 \\
Cold & 16 & Nasal congestion & 5 \\
Abdominal pain & 16 & Muscular pains & 5 \\
Back pain & 10 & Earache & 4 \\
Giddiness & 9 & Painful arm & 4 \\
Leg pain & 8 & Breast pain & 4 \\
Headache & 8 & Neck pain & 4 \\
\hline
\end{tabular}

TABLE II-Results of questionnaire as numbers of patients (and percentages)

\begin{tabular}{|c|c|c|c|c|c|}
\hline & & \multicolumn{2}{|c|}{ Positive consultations } & \multicolumn{2}{|c|}{ Negative consultations } \\
\hline & & $\begin{array}{l}\text { Treated } \\
(n=50)\end{array}$ & $\begin{array}{l}\text { Not treated } \\
(n=50)\end{array}$ & $\begin{array}{l}\text { Treated } \\
(\mathrm{n}=50)\end{array}$ & $\begin{array}{l}\text { Not treated } \\
(n=50)\end{array}$ \\
\hline \multicolumn{6}{|c|}{$\begin{array}{l}\text { (1) How well were you able to tell } \\
\text { him about your problem? }\end{array}$} \\
\hline & $\begin{array}{l}\text { Very well } \\
\text { Quite well } \\
\text { Not very well } \\
\text { Poorly }\end{array}$ & $\begin{array}{l}40(80) \\
10(20)\end{array}$ & $\begin{array}{c}44(90) \\
3(6) \\
2(4)\end{array}$ & $\begin{array}{c}25(60) \\
13(31) \\
4(9)\end{array}$ & $\begin{array}{c}29(60) \\
15(31) \\
4(8)\end{array}$ \\
\hline \multirow{2}{*}{ (2) } & $\begin{array}{l}\text { How well do you think the doctor } \\
\text { understood your problem? }\end{array}$ & & & & \\
\hline & $\begin{array}{l}\text { Very well } \\
\text { Quite well } \\
\text { Not very well } \\
\text { Poorly }\end{array}$ & $\begin{array}{r}43(88) \\
6(12)\end{array}$ & $\begin{array}{l}46(94) \\
3(6)\end{array}$ & $\begin{array}{r}23(55) \\
14(33) \\
5(12)\end{array}$ & $\begin{array}{l}25(52) \\
19(40) \\
3(6) \\
1(2)\end{array}$ \\
\hline \multirow{2}{*}{ (3) } & $\begin{array}{l}\text { How much better do you feel } \\
\text { having seen the doctor? }\end{array}$ & & & & \\
\hline & $\begin{array}{l}\text { Completely } \\
\text { Much } \\
\text { A little } \\
\text { No better }\end{array}$ & $\begin{array}{r}7(15) \\
21(44) \\
14(29) \\
6(12)\end{array}$ & $\begin{array}{l}10(21) \\
18(33) \\
18(37) \\
2(4)\end{array}$ & $\begin{array}{l}2(5) \\
12(30) \\
15(38) \\
11(27)\end{array}$ & $\begin{array}{l}3(6) \\
10(21) \\
12(25) \\
22(47)\end{array}$ \\
\hline \multicolumn{6}{|c|}{$\begin{array}{l}\text { (4) Have you been helped by seeing } \\
\text { the doctor? }\end{array}$} \\
\hline & $\begin{array}{l}\text { A lot } \\
\text { A little } \\
\text { Slightly } \\
\text { Not at all }\end{array}$ & $\begin{array}{l}23(79) \\
4(14) \\
1(3) \\
1(5)\end{array}$ & $\begin{array}{c}35(73) \\
10(21) \\
3(6)\end{array}$ & $\begin{array}{l}13(52) \\
7(28) \\
2(8) \\
3(12)\end{array}$ & $\begin{array}{r}10(30) \\
10(30) \\
8(24) \\
5(15)\end{array}$ \\
\hline
\end{tabular}

*Not all patients answered the questionnaire. In particular, the last question was added to the questionnaire after the investigation had started.

TABLE III-Numbers (and percentages) of patients who got better

\begin{tabular}{|c|c|c|c|c|}
\hline & \multicolumn{2}{|c|}{ Positive consultations } & \multicolumn{2}{|c|}{ Negative consultations } \\
\hline & $\begin{array}{l}\text { Treated } \\
(\mathrm{n}=50)\end{array}$ & $\begin{array}{c}\text { Not treated } \\
(n=50)\end{array}$ & $\begin{array}{l}\text { Treated } \\
(n=50)\end{array}$ & $\begin{array}{c}\text { Not treated } \\
(\mathrm{n}=50)\end{array}$ \\
\hline $\begin{array}{l}\text { Men } \\
\text { Women }\end{array}$ & $\begin{array}{l}14 \\
18\end{array}$ & $\begin{array}{l}10 \\
22\end{array}$ & $\begin{array}{r}5 \\
16\end{array}$ & $\begin{array}{l}9 \\
9\end{array}$ \\
\hline $\begin{array}{l}\text { Total } \\
\text { Grand total }\end{array}$ & 32 & 32 & 21 & 18 \\
\hline
\end{tabular}

p $<0.001$. patients who saw the doctor of their choice, $64(57 \%)$ got better compared with $40(45 \%)$ of those who did not $(p=0 \cdot 10)$. Of those patients who failed to get better, no significant difference was found in the rates of return to see a doctor between those who received a positive or a negative consultation $(p=0.5)$, nor in the rates of return to see me rather than another doctor $(p=0 \cdot 16)$.

\section{Discussion}

The findings of this investigation show that there is a point in being positive: patients who present with minor illness show greater satisfaction, and are more likely to have recovered from their illness within two weeks if they receive a positive rather than a negative consultation.

The only treatment offered in this study was the doctor himself, acting either directly or through a placebo, and neither method was more successful than the other. The results show the effect of one particular doctor in the consultation when he is used in a particular way. With a positive approach $64 \%$ of patients recovered from their illness within two weeks. Possibly a more positive approach, or a different approach, or one using a different doctor, would have produced a different result.

Ideally the positive consultation should have been compared with a normal consultation. This proved difficult because my usual consulting style is positive. The artificial negative consultation consequently devised was negative in the sense that at the end of the consultation (after the patient had been heard, examined, and diagnosed), an element of doubt was introduced by the perfectly truthful statement that "I cannot be certain what is the matter with you" and if treatment was given, that "I am not sure that the treatment will have an effect." The realisation that the doctor did not know seemed to have had an adverse effect on some patients, although others seemed to ignore the statements and not to realise what had been said.

Much of the minor illness in this investigation might have been expected to resolve spontaneously, and it is surprising to find that after two weeks $61 \%$ of those patients receiving a negative consultation said that they were not better. I considered the possibility that some patients reacted to receiving a negative consultation by saying they were not better when in fact they were. Such a happening should have resulted in fewer patients returning to see a doctor from the negative group than from the positive group. In fact, no difference was found in the rates of return to see the doctor between the positive and negative consultation groups, or in the return rates to see me rather than another doctor. My subjective assessment of the consultation, which correlated with patient satisfaction but not with recovery from illness, suggests that a good doctor patient relationship alone is not sufficient to ensure recovery from illness.

This work has shown once again ${ }^{8}$ that for this group of "temporarily dependent" patients, 5 who made up $43 \%$ of consultations for illness in the original study, a prescription is no more effective in producing patient satisfaction or recovery from illness than not giving one.

In the past doctors treated their patients in a positive and authoritarian manner because of its supposed effectiveness. Historically the doctor himself was the most effective treatment available. Today we like to think that our treatment in general practice is based on scientific principles, although we do not really know how effective it is. In view of the difficulty in making a firm diagnosis, ${ }^{2-6}$ the considerable variation in the reporting of almost all categories of illness, ${ }^{49-12}$ and the evidence that often antibiotics, ${ }^{13}$ tranquillisers, ${ }^{14}$ decongestants, ${ }^{15}$ expectorants, ${ }^{16}$ and so on are no better than a placebo, possibly the doctor himself is still the most effective treatment available.

Recent changes in society are mirrored in a new doctor-patient relationship. The old authoritarian consultation has given way to a more flexible and equal relationship. The new consultation is often non-authoritarian, ${ }^{17}$ non-paternalistic, ${ }^{18}$ communicating, honest, and sharing, even of uncertainty-an attempt to make a rational negotiation between doctor and patient. Although this new approach may lack the positive assurance of the traditional consulta- 
tion, it would be wrong to assume that it is the same as my negative consultation, which was presumably more negative. But there are similarities and there is change, and we do not know whether the substitution of rationality for authority in the new consultation has adversely affected the placebo action. That this is a possibility is suggested by the statement of Pendleton et al that: "there may be costs involved for the patients who are deprived of the anxiety reducing effects of a powerful healer." 17

For a thousand years the action of the placebo has made vast numbers of patients feel better; have we today produced a consultation in which the placebo does not act? If we are going to practise, and even more important to teach, the shared consultation we must be able to show clearly what effect it has not only on patient satisfaction but also on recovery from illness.

I thank Dr M J Campbell, of the Department of Community Medicine at Southampton University, who was responsible for the statistical work, Dr F J Davidson for his original idea, Mrs J Taverner, pharmacist; my colleagues at the Aldermoor Health Centre, particularly Dr C B Freer, Dr G K Freeman, Dr R H Jones, and Professor D J G Bain; the receptionists, particularly Mrs L Such; the secretaries, particularly Mrs P Hibberd; and the patients.

\section{References}

1 Balint M. The doctor, his patient and the illness. Tunbridge Wells: Pitman Medical, 1957:1-8. 2 Eimmerl TS. Aspects of general practice 1949-1960. MD thesis, University of Liverpool, 1962.

3 Crombie DL. Diagnostic process. 7 Coll Gen Pract 1963;6:582.

4 Research Committee of process. $f$ Coll Gen Pract 1963;6:582. recording of morbidity. $\mathcal{J}$ Coll Gen Pract 1958;1:107-28.

Thomas KB. Temporarily dependent patient in general practice. BrMed f 1974;i:625-6.

6 McNair Wilson R. The belooed physician. London: John Murray, 1926

7 Treadway J. Patient satisfaction and the content of general practice consultations. $\mathcal{F} R$ Coll Gen Pract 1983;33:769-71.

8 Thomas KB. The consultation and the therapeutic illusion. BrMed $\mathcal{f}$ 1978;i:1327.

Shepherd M, Cooper B, Brown AC, Kalton G. Psychiatric illness in general practice. London: Oxford University Press, 1966.

10 Ward T, Knowelden J, Sharrard WJW. Low back pain. $\mathcal{I}$ R Coll Gen Pract 1968;15:128.

11 Howard CRG. The problems of defining the extent of morbidity in general practice. $\mathcal{F}$ Coll Gen Pract 1959;2:119.

2 Lees DS, Cooper MH. The work of the general practitioner. 7 Coll Gen Pract 1963:6:408.

13 Stott NCH, West RR. Randomised controlled trial of antibiotics in patients with cough and purulent sputum. BrMed J 1976;ii:556-9.

14 East of Ireland Faculty of the RCGP and the Department of Community Health, University of Dublin. A double blind randomized control trial of diazepam. $\mathcal{I} R$ Coll Gen Pract 1983;33:
(a) 635-6.

15 Bain DJG. Can the clinical course of acute otitis media be modified by systemic decongestant or antihistamine treatment. Br Med $\mathcal{J}$ 1983;287:654.

16 Anonymous. British national formulary. London: BMA and Pharmaceutical Society of Great Britain, 1983:120.

17 Pendleton D, Schofield T, Tate P, Havelock P. The consultation: an approach to leaming and reaching. Oxford: Oxford University Press, 1984:97-103.

18 Zander L. From paternalism to patient autonomy. Practitioner 1985;229:1087-9.

(Accepted 10 March 1987)
Our three partner vocational training practice has 5550 patients with an average age-sex distribution. Threshold diastolic (phase $V$ ) pressures of $100 \mathrm{~mm} \mathrm{Hg}$ and $105 \mathrm{~mm} \mathrm{Hg}$ have been established as the definition of hypertension in the age groups $40-59$ and 60 and over, respectively, for the past decade in the practice. ${ }^{\prime}$ The diagnosis of diabetes is confirmed by an increased blood glucose concentration (fasting specimen $\geqslant 7 \mathrm{mmol} / \mathrm{l}$ or two hour postprandial concentration $\geqslant 10 \mathrm{mmol} / \mathrm{l}$ ) and glycosylated haemoglobin $\geqslant 10 \%$.

In the autumn of 1984 the case records of every patient aged 40-64 were examined except of those already recorded as being hypertensive on the disease register. ${ }^{2}$ All patients who did not have a normal blood pressure reading entered in the medical record within the previous 18 months were invited by letter to attend for a blood pressure and urine check.

The screening was performed by nurses trained in the use of a random zero sphygmomanometer. Patients who had a high (rechecked) reading or glycosuria were referred to the family doctor for further investigation and management.

There were 105 hypertensive patients and 22 diabetics, known already from our usual case finding policy (including four men who had both diseases). Only $15(3 \%)$ of the 572 attenders at the subsequent screening clinics were found to be hypertensive (12 patients) or diabetic (three). None had both diseases. All three diabetics and seven hypertensive patients were aged over 60 .

The screening for this study took over three months to organise and implement; extra time, labour, and funds were required; and only one in $\mathbf{4 0}$ attenders had an (asymptomatic) abnormality. Opportunistic case finding by family doctors therefore remains probably the most feasible and cost effective measure in the community for the foreseeable future.-ROBERT FAIRLEY, general practitioner, Health Centre, Bridge of Allan. (Accepted 13 March 1987)

I am grateful to the Forth Valley general practitioner research group, who provided the extra staff and funds for the screening surveys. I thank Miss Seonaid McLean and Miss Donna Kennedy for their diligent clerical work and both nursing sisters, Mrs Julia Harrower and Mrs Judith Morgan, who performed the screening with enthusiasm. Mrs Margaret Prentice typed the manuscript.

1 Barber JH, Beevers DG, Fife $\mathrm{R}$, et al. Blood pressure screening and supervision in general practice. BrMed F 1979;i:843-6.

2 Fairley R. Compiling a practice disease register-the prevalence of incidental problems. $\mathcal{I} R \mathrm{Coll}$ Gen Pract 1984;34:213-5. 